\title{
Association between type of training and risk of asthma in elite athletes
}

\author{
Ilkka J Helenius, Heikki O Tikkanen, Tari Haahtela
}

\begin{abstract}
Background - Intensive endurance training has been associated with a high prevalence of symptoms compatible with asthma in elite athletes. It is not known, however, whether there is an association between the type of training for competitive events and the risk of asthma in highly trained athletes.

Methods - Two hundred and thirteen track and field athletes, mostly from Finnish national teams, and 124 controls of the same age completed a respiratory symptom questionnaire. Positive answers to physician diagnosed asthma were confirmed by personal interviews. The athletes were divided into two groups depending on whether they were speed and power athletes $(n=106)$ or long distance runners $(n=107)$.
\end{abstract}

Results - According to a logistic regression model the prevalence of physician diagnosed asthma was not associated with age, sex, or a family history of asthma. Long distance runners (OR 6.7; 95\% CI 2.1 to 22.1) and speed and power athletes (OR $3.2 ; 95 \%$ CI 0.90 to 11.4 ) had a higher prevalence of physician diagnosed asthma than control subjects. Physician diagnosed asthma was found in $\mathbf{1 8}$ of 107 long distance runners $(17 \%)$, in nine of 106 speed and power athletes $\left(8 \% ; p=0.07\left(\chi^{2}\right.\right.$ test $\left.)\right)$, and in four of 124 controls $\left(3 \% ; p<0.0004\left(\chi^{2}\right.\right.$ test for trend)).

Conclusions - The prevalence of physician diagnosed asthma is high in elite athletes and an association with the competitive event is suggested with long distance runners having a greater risk of developing asthma than speed and power athletes. This may be due to prolonged hyperventilation and increased exposure to inhalant allergens and irritants during endurance training and competition.

(Thorax 1997;52:157-160)

Keywords: asthma, training, sports.
High prevalence rates of asthma have recently been reported among highly trained athletes. ${ }^{1-6}$ This is especially true in endurance events such as cross country skiing, ${ }^{245}$ swimming, ${ }^{6}$ and long distance running ${ }^{3}$ in which ventilation is increased for long periods of time during training and competition. In cross country skiers strenuous training at low temperatures may contribute to the increased occurrence of asthma. ${ }^{2}$ It is not known, however, whether there is an association between the type of training undertaken for the competitive event and risk of asthma in highly trained athletes.

Long distance runners undergo lengthy training and competition with prolonged hyperventilation. Training in countries with four distinct seasons means repeated breathing of cold air in winter while, during spring and summer, the atopic athletes are exposed to pollen allergens. The speed and power track and field athletes, however, train by different methods consisting of high intensity performance of short duration which increases the ventilation only for short periods of time.

A study was undertaken to examine the prevalence of physician diagnosed asthma in two different athlete groups whose training and competition are very different from each other, and the results were compared with a control group.

\section{Methods}

SUBJECTS

Two hundred and thirteen elite track and field athletes and 124 medical students volunteered to participate in the study. The athletes were divided into two groups according to the type of training: 106 speed and power athletes and 107 long distance runners. ${ }^{7}$ Long distance runners specialised in distances from 800 metres to the marathon while the main events of the speed and power athletes were sprinting (100 400 metres, hurdles; $n=44$ ), jumping or decathlon (high, long and triple jump, pole vault, decathlon, heptathlon; $\mathrm{n}=35$ ), and throwing (javelin, discus, shot put, hammer; $n=27$ ). The control group comprised 124 medical students. Most of the athletes were members of the Finnish national teams, whereas none of the medical students were involved in active competitive sports. The characteristics of the three study groups are given in table 1 .

All subjects gave their written consent and the study protocol was approved by the local ethics committee.

\section{STUDY DESIGN}

The study was carried out during February and March 1994 (long distance runners), February
Mean (SD) age (years)

Members of Finnish national teams, \% (n)

Mean (SD) training in previous year $(\mathrm{km}, \mathrm{h})$

${ }^{1}$ Amount in kilometres; ${ }^{2}$ amount in hours.

\begin{tabular}{lll}
$\begin{array}{l}\text { Long distance } \\
\text { runners } \\
(n=107)\end{array}$ & $\begin{array}{l}\text { Speed and power } \\
\text { athletes } \\
(n=106)\end{array}$ & $\begin{array}{l}\text { Controls } \\
(n=124)\end{array}$ \\
\hline $84 / 23$ & $75 / 31$ & $73 / 51$ \\
$23.0(5.5)$ & $21.5(3.5)$ & $25.6(3.8)$ \\
$66(71)$ & $79(84)$ & - \\
$9.2(4.3)$ & $8.9(4.4)$ & - \\
$4160(1690)^{1}$ & $530(150)^{2}$ & - \\
\hline
\end{tabular}


Table 2 Prevalence (\%) of physician diagnosed asthma and allergy (rhinoconjunctivitis, atopic eczema), use of anti-asthmatic medication, family history of asthma, and exercise induced bronchial symptoms in the study groups

\begin{tabular}{|c|c|c|c|c|c|c|c|}
\hline \multirow[b]{2}{*}{ Group } & \multirow[b]{2}{*}{ Asthma } & \multirow[b]{2}{*}{ Allergy } & \multirow[b]{2}{*}{ Asthma medication } & \multirow[b]{2}{*}{ Asthma in family } & \multicolumn{3}{|c|}{ Exercise induced bronchial symptoms } \\
\hline & & & & & Cough & Breathlessness & Wheeze \\
\hline Long distance runners & $17(18) \ddagger$ & $37(40)^{*}$ & $21(23) \ddagger$ & $11(12)$ & $41(44) \ddagger$ & $31(33) \ddagger$ & $29(31) \ddagger$ \\
\hline $\begin{array}{l}\text { Speed and power athletes } \\
\text { Sprinters } \\
\text { Jumpers, decathletes } \\
\text { Throwers }\end{array}$ & $\begin{array}{c}8(9) \\
7(3) \\
6(2) \\
15(4)^{*}\end{array}$ & $\begin{array}{l}26(28) \\
23(10) \\
26(9) \\
33(9)\end{array}$ & $\begin{aligned} 10 & (11) \\
9 & (4) \\
6 & (2) \\
19 & (5) \dagger\end{aligned}$ & $\begin{array}{c}10(11) \\
16(7) \\
9(3) \\
4(1)\end{array}$ & $\begin{array}{l}26(28) \ddagger \\
30(13) \ddagger \\
17(6) \\
33(9) \ddagger\end{array}$ & $\begin{array}{l}23(24)^{*} \\
27(12)^{*} \\
23(8) \\
15(4)\end{array}$ & $\begin{array}{l}14(15)^{*} \\
16(7)^{*} \\
11(4) \\
15(4)\end{array}$ \\
\hline Controls & $3(4)$ & $24(30)$ & $4(5)$ & $12(15)$ & $7(9)$ & $12(15)$ & $6(7)$ \\
\hline
\end{tabular}

Values in parentheses are numbers of subjects.

$* \mathrm{p}<0.05 ; \dagger \mathrm{p} \leq 0.01 ; \neq \mathrm{p}<0.001$ versus controls.

and March 1995 (speed and power athletes), and September to October 1995 (controls). Athletes who attended the Finnish national team camps during the study period were asked to complete the questionnaires and, in addition, athletes from four Finnish track and field clubs from the cities of Helsinki and Espoo were invited to participate (elite athletes but outside the Finnish national team). Two courses of medical students randomly selected to serve as controls completed the questionnaires during their compulsory lectures. None of the athletes or controls refused to fill in the questionnaire. If the subject stated that he or she had physician diagnosed asthma this was confirmed afterwards by a personal interview.

QUESTIONNAIRE

All participants filled in a questionnaire prepared especially for the study and based on the recommendations of Ferris. ${ }^{8}$ Questions concerned diagnoses of asthma and allergy made by a physician, exercise induced bronchial symptoms, use of anti-asthmatic medication, family history of asthma, competitive status, and smoking habits. Subjects were asked the following questions: (1) "Do you have the following disorders diagnosed by a physician: (a) asthma, (b) allergy (name condition)?" If the subject answered positively to the first alternative he or she was considered to have asthma. Allergy was registered if allergic rhinoconjunctivitis or atopic eczema were reported. (2) "How often do you have cough, shortness of breath or wheeze in connection to exercise (each symptom asked separately): (a) daily, (b) weekly, (c) sometimes, (d) never or only in connection to respiratory infections?" (3) "Do you use anti-asthmatic medication (name preparations)?" (4) "Do your father, mother or siblings have asthma diagnosed by a physician?" (5) "Have you been a member of the Finnish national team?" (6) "Are you (a) a current smoker or stopped smoking less than six months ago, (b) an ex-smoker or stopped smoking more than six months ago, (c) a life time non-smoker?"

STATISTICAL METHODS

Odds ratios (OR) for the presence of disease and their $95 \%$ confidence intervals (95\% CI) for different athlete groups compared with controls were analysed using a logistic regression model (BMDP Statistical Software). Age, sex, and family history of asthma were included as potential confounding factors in the analysis. Differences in the prevalence rates and trends in prevalence rates were examined using the $\chi^{2}$ test and $\chi^{2}$ test for trend. Two tailed $\mathrm{p}$ values of $<0.05$ were considered significant.

\section{Results}

The occurrence of asthma and allergies (rhinoconjunctivitis, atopic eczema) as diagnosed by a physician, the use of anti-asthmatic medication, a family history of asthma, and exercise induced bronchial symptoms are shown in table 2.

According to a logistic regression model, the prevalence of physician diagnosed asthma was not associated with age, sex, or a family history of asthma in the study groups. Compared with the controls, speed and power athletes (OR 3.2; $95 \%$ CI 0.90 to 11.4 ) and long distance runners (OR 6.7 ; 95\% CI 2.1 to 22.1 ) had higher prevalences of asthma (table 3 ).

Asthma, allergies, use of medication, and exercise symptoms were all significantly more common in the long distance runners than in the control subjects (table 2). In the speed and power athletes exercise symptoms were significantly more common while asthma and use of medication tended to be more common than in the control subjects $(\mathrm{p}=0.08$ and 0.06 , respectively). A difference in the prevalence of asthma was observed between the long distance runners $(18$ of $107,17 \%)$ and speed and power athletes (nine of $106,8 \%$ ), although it did not quite reach statistical significance $(p=0.07)$. Long distance runners also used significantly

Table 3 Relative risks (OR) and confidence intervals (95\% CI) for physician diagnosed asthma when age, sex, family history of asthma, and type of training are considered as independent covariates in a logistic regression analysis

\begin{tabular}{|c|c|c|c|}
\hline \multirow[b]{2}{*}{ Characteristic } & \multicolumn{3}{|c|}{ Physician diagnosed asthma } \\
\hline & $O R$ & $95 \% C I$ & $p$ \\
\hline \multicolumn{4}{|l|}{ Age (years) } \\
\hline Below 20 & 1.0 & & \\
\hline $\begin{array}{l}20-25 \\
\text { Over } 25\end{array}$ & 1.4 & 0.55 to 3.75 & 0.46 \\
\hline \multicolumn{4}{|l|}{ Sex } \\
\hline $\begin{array}{l}\text { Women } \\
\text { Men }\end{array}$ & 1.0 & 063 to 336 & \\
\hline \multicolumn{4}{|l|}{ Family history of asthma } \\
\hline $\begin{array}{l}\text { No family history } \\
\text { Family history }\end{array}$ & 1.0 & 078 to 5.84 & 0.14 \\
\hline \\
\hline Control subjects & 1.0 & & \\
\hline Speed and power sports & 3.2 & 0.90 to 11.4 & 0.07 \\
\hline Long distance running & 6.7 & 2.1 to 22.1 & 0.002 \\
\hline
\end{tabular}


more anti-asthmatic medication and reported cough and wheeze associated with exercise significantly more often than speed and power athletes.

All the asthma parameters (diagnosis, medication, exercise symptoms) showed an increasing trend from the control subjects, to the speed and power athletes, to the long distance runners $\left(\chi^{2}\right.$ test for trend, $\left.\mathrm{p}<0.0004\right)$. Cough was the most commonly reported exercise induced symptom among the long distance runners $(41.1 \%)$ and speed and power athletes $(26.4 \%)$ while shortness of breath was the symptom most frequently reported by the controls $(12.1 \%)$.

Most asthmatic subjects reported physician diagnosed allergy: 15 of the 18 asthmatic long distance runners, seven of the nine speed and power athletes, and three of the four control subjects. Allergies also tended to increase from the controls, to the speed and power athletes, to the long distance runners $(\mathrm{p}=0.03$ for trend). A family history of asthma in first degree relatives was similar in all three groups (table 2).

Fifteen of the 107 long distance runners (14\%), eight of the 106 speed and power athletes $(8 \%)$, and four of the 124 controls (3\%) used anti-asthmatic medication regularly and reported a diagnosis of asthma. In all groups the most commonly used drugs were inhaled $\beta_{2}$ agonists and corticosteroids. In addition, eight of the long distance runners $(7 \%)$, three of the speed and power athletes (3\%), and one of the controls $(1 \%)$ used anti-asthmatic medication without having reported physician diagnosed asthma (table 2). Five of these eight long distance runners were allergic and all reported exercise induced bronchial symptoms. Similarly, of the three speed and power athletes using medication without diagnosis two reported allergies and all had exercise induced symptoms. One young woman in the control group used anti-asthmatic medication without a diagnosis of asthma and she reported both allergies and exercise symptoms.

None of the long distance runners was a current smoker and two were ex-smokers. Of the speed and power athletes one was a current smoker and one an ex-smoker, whereas of the control subjects nine were current smokers and 20 ex-smokers.

\section{Discussion}

We have previously reported a high prevalence of self-reported asthma and symptoms compatible with exercise induced asthma in runners. ${ }^{3}$ The results of the present study show that the prevalence of physician diagnosed asthma in elite athletes is associated with the type of competitive event. According to a logistic regression model the prevalence of physician diagnosed asthma was not associated with age, sex, or a family history of asthma in the study groups.

VALIDITY OF THE DATA

The studied outcome variable, physician diagnosed asthma, was based on a structured ques- tionnaire and the same criteria were employed for the two athlete groups and the control group. Positive answers to physician diagnosed asthma were confirmed afterwards in all cases by personal interviews. Of the control group, $3 \%$ had asthma which is a similar prevalence rate to that of the Finnish population in general. ${ }^{910}$ In both athlete groups participants were dedicated athletes as indicated by the amount of training undertaken. In addition, most of the athletes were members of the Finnish national teams, whereas none of the controls were involved in active competitive sports.

The control group included more women than the two athlete groups and they were also somewhat older than the athletes. However, according to the logistic regression model age and sex were not significantly associated with the prevalence of asthma. The controls completed their questionnaires in different seasons of the year from the two athlete groups but it is unlikely that this substantially influenced the results.

COMPARISON WITH EARLIER DATA

About $9 \%$ of the athletes in the Australian Olympic teams of 1976 and 1980, with a predominance of swimmers, reported asthma in a physical examination. ${ }^{6}$ In $19844.4 \%$ of the athletes in the United States Olympic team were reported to have asthma. ${ }^{1}$ In $19863.7 \%$ of 2060 Swiss athletes in various competitive events reported asthma in a questionnaire. ${ }^{11}$ Larsson $e t a l^{4}$ and Heir et $a l^{5}$ also found that $15 \%$ and $14 \%$, respectively, of skiers reported a past or present history of physician diagnosed asthma in a questionnaire. The lifetime prevalence of physician diagnosed asthma was $2.4 \%$ in 1282 former elite athletes from various competitive sports. ${ }^{12}$ However, these athletes had participated actively in competitive sports more than 30 years ago when functional diagnostic procedures for asthma were less accurate. In our previous study $16 \%$ of Finnish elite runners reported asthma. ${ }^{3}$ In the present study $17 \%$ of long distance runners and $8 \%$ of speed and power track and field athletes had asthma as diagnosed by a physician. It is quite possible that differences in the type of sport could explain some of the conflicting results in previous studies.

The high prevalence of asthma and exercise induced bronchial symptoms requires frequent use of anti-asthmatic drugs by elite athletes. Larsson $e t \mathrm{al}^{4}$ found that $18 \%$ of cross country skiers used anti-asthmatic medication and Heir et $a l^{5}$ found that $22 \%$ of skiers used such medication. In both studies the frequency of use was a reflection of the high prevalence of exercise induced respiratory symptoms. In the present study $21 \%$ of long distance runners and $10 \%$ of speed and power athletes reported having used anti-asthmatic drugs. Most of these athletes reported asthma, and those without physician diagnosed asthma reported symptoms compatible with exercise induced asthma.

A substantial number of athletes without an asthma diagnosis reported bronchial symptoms. Of long distance runners only four of the 
14 who reported all three bronchial symptoms had physician diagnosed asthma. The corresponding figures were three of five speed and power athletes and three of four controls. Combined with a frequent use of anti-asthmatic medication, these findings may indicate undiagnosed asthma especially among the long distance runners. Indeed, when five of the athletes (four long distance runners and one speed and power athlete) without a diagnosis of asthma performed heavy exercise challenge tests at low temperature combined with lung function testing two had exercise induced bronchospasm. ${ }^{13}$

The high prevalence of asthma and bronchial symptoms in athletes reported here and in other studies $^{1-6}$ can be explained in several ways. It seems unlikely that athletes with a genetic susceptibility to asthma will tend to take up sports, especially long distance running, more often than individuals without such a predisposition. In the present study a family history of asthma was similar in the three study groups.

Bronchial symptoms without bronchospasm may be "normal" sequelae of vigorous activity. However, we do not believe this to be the case based on the exercise challenge test results published previously in which heavy exercise for seven minutes at low temperature caused bronchospasm in a quarter of 32 elite nonasthmatic runners. ${ }^{13}$ Athletes who train hard, particularly long distance runners, are frequently exposed to factors such as cold air $^{14}$ and aeroallergens ${ }^{15}$ which are known to exacerbate bronchoconstriction.

Our study may be criticised for exaggerating differences in the occurrence of respiratory symptoms between the athletes and control subjects because the controls are exposed to the triggers of bronchospasm less frequently and may therefore experience fewer bronchial symptoms. The reaction of control subjects to comparable climatic and hard exercise con- ditions is not known, but it would be difficult to carry out similar tests on control subjects to those performed on athletes without competitive training.

In conclusion, our findings suggest an association between the risk of asthma and the competitive event undertaken by elite track and field athletes. The reason is obscure but the observation may be explained by differences in the amount of ventilation and exposure to inhalant allergens and irritants during these events.

We thank Associate Professor Seppo Sarna (Department of Public Health, University of Helsinki) for help with the statistica analyses and all the athletes who participated in the study. This work was supported by grants from the Väinö and Laino Kiv Foundation, the Allergy and Asthma Federation, the Finnish Ministry of Education, and the Finnish Olympic Committee.

1 Voy RO. The US Olympic Committee experience with exercise-induced bronchospasm, 1984. Med Sci Sport Exerc 1986;18:328-30.

2 Larsson K, Ohlsen P, Larsson L, Malmberg P, Rydstrom $\mathrm{PO}$, Ulriksen H. High prevalence of asthma in cross country skiers. $B M F$ 1993;307:1326-9.

3 Tikkanen HO, Helenius IJ. Asthma in runners. BMf 1994 309:1087.

4 Larsson L, Hemmingsson P, Boethius G. Self-reported obstructive airway symptoms are common in young crosscountry skiers. Scand 7 Med Sci Sports 1994;4:124-7.

5 Heir T, Oseid S. Self-reported asthma and exercise-induced asthma symptoms in high-level competitive cross-country skiers. Scand 7 Med Sci Sports 1994;4:128-33.

6 Fitch KD. Management of allergic athletes. $\mathcal{F}$ Allergy Clin Immunol 1984;73:722-7.

7 Astrand PO, Rodahl K, eds. Textbook of work physiology. 3rd edn. New York: McGraw-Hill, 1986:412-15.

8 Ferris BG. Epidemiology standardization project. Am Rev Respir Dis 1978;118(Suppl):7-53.

9 Haahtela T, Lindholm H, Björksten F, Koskenvuo K, Laitinen LA. Prevalence of asthma in Finnish young men. tinen LA. Prevalence $1990 ; 301: 266-8$.

10 Ministry of Social Affairs and Health. Asthma programme in Finland 1994-2004. Clin Exp Allergy 1996;26(Suppl 1): in Fin.

11 Helbling A, Muller U. Asthma Bronchiale bei Spitzensportlern. Schweiz $Z$ Sportmed 1991;39:77-81.

12 Kujala UM, Sarna S, Kaprio J, Koskenvuo M. Asthma and other pulmonary diseases in former elite athletes. Thorax other pulmonary

13 Helenius IJ, Tikkanen HO, Haahtela T. Exercise-induced bronchospasm at low temperature in elite runners. Thorax 1996;51:628-9.

14 Strauss RH, McFadden ERJ, Ingram RHJ, Jaeger JJ. Enhancement of exercise-induced asthma by cold air. $N$ Engl f Med 1977;297:743-7

15 Karjalainen J, Lindqvist A, Laitinen LA. Seasonal variability of exercise-induced asthma especially outdoors. Effect of birch pollen allergy. Clin Exp Allergy 1989;19:273-8. 